\title{
Informational approach of family spin-offs in the funding process of innovative projects: an empirical verification
}

\author{
Francesco Campanella, Manlio Del Giudice and Maria Rosaria Della Peruta*
}

\author{
* Correspondence: \\ mariarosaria.dellaperuta@unina2.it \\ Department of Economics, Second \\ University of Naples, Naples, Italy
}

\begin{abstract}
In recent years, the increase in competitiveness, as a result of the economic globalization and crisis, has caused the bankruptcy of many Italian small family businesses working in traditional industries. Meanwhile, family firms that have been working in a perspective of process and product innovation have been able to maintain a durable competitive advantage. In particular, enterprises that have shown a particular vitality are spin-offs, founded by an innovator entrepreneur with an academic background: these have often found their funding in self-financing and family and public resources in the pre-seed and seed stages of the project. However, these spin-offs often have difficulty financing the start-up phase of the project with external resources due to risk and informational opacity related to innovative processes. The literature grounded on innovation funding has highlighted the informative opacity problem mainly caused by family entrepreneurs' difficulty to communicate innovation characteristics and commercial potential to financial markets and by the inability to identify individuals who are more available to finance innovative investments. Therefore, it is particularly difficult for investors to assess family small- and medium-sized enterprises' economic feasibility of innovative projects. These difficulties have increased in recent years partly due to the economic crisis that, on the one hand, has made venture capitalists more risk averse and, on the other, has contributed to a gradual hardening of enterprises' creditworthiness system adopted by financial brokers. The research focuses on the analysis of the information problem that hinders the external financing aimed at innovation in family academic spin-offs. In particular, the authors intend to investigate the information dynamics between the innovator entrepreneur and external financiers. So, this research is useful to better identify what informative gaps impede innovative investments in Italy among innovator entrepreneurs and founders through venture capital and debt capital.
\end{abstract}

\section{Background}

In recent years, the increase in competitiveness, as a result of the economic globalization and crisis, has caused the bankruptcy of many Italian small family businesses working in traditional industries. Meanwhile, family firms that have been working in a perspective of process and product innovation have been able to maintain a durable competitive advantage.

In particular, enterprises that have shown a particular vitality are spin-offs, founded by an innovator entrepreneur with an academic background: these have often found

\section{Springer}

(c) 2013 Campanella et al.; licensee Springer. This is an Open Access article distributed under the terms of the Creative Commons Attribution License (http://creativecommons.org/licenses/by/2.0), which permits unrestricted use, distribution, and reproduction in any medium, provided the original work is properly cited. 
their funding in self-financing and family and public resources in the pre-seed and seed stages of the project. However, these spin-offs often have difficulty financing the start-up phase of the project with external resources due to risk and informational opacity related to innovative processes.

In particular, the risk of industrial $R \& D$ is caused by the high probability that the project will fail and by the limited availability of collateral for innovative small- and medium-sized enterprises (SMEs) with a high concentration of intangible assets.

Informational opacity in innovative processes, instead, is caused by the following:

1. The inventor entrepreneur's difficulty to communicate the commercial features and the potential of innovation in the financial market.

2. The entrepreneur's difficulty to assess the expected cash flow and the time of return on investment.

3. The entrepreneur's inability to identify the actors that are more willing to finance innovative investments.

Thus, these factors complicate both the communication of economic and financial validity and the identification of the financier (bank or venture capitalist) that is willing to implement and evaluate the innovative project.

These difficulties have increased in recent years partly because of the economic crisis that has made venture capitalists more risk averse and has contributed to a gradual tightening of the assessment systems of firm creditworthiness adopted by financial intermediaries.

A study by the Bank of Italy on a sample of 4,500 manufacturing firms shows that in our country, small innovative businesses have a lower debt level (leverage) and a higher incidence of internal financial resources (cash flow) than small businesses that do not innovate. These differences do not emerge in the group of large companies. This result is consistent with the presence of major information problems for smaller firms. In particular, small business managers show greater difficulties in communicating with the financial market at the time of funding innovative projects.

Based on these observations, the research focuses on the analysis of the informational problem in Italy, which hinders external funding of innovation in family SMEs originating from academic spin-offs. In particular, the authors intend to investigate the informational dynamics between innovator entrepreneurs and the managers of lending companies in the critical moment of funding an innovative project. Therefore, by administering a questionnaire to a significant sample of founders of family spin-offs and financial managers and comparing the results of the interviews, the aim is to verify the following:

1. If such information is deemed relevant by innovator entrepreneurs to assess financing worthiness from the seed stage to the expansion stage of the project.

2. What information relating to innovative projects is required by the managers of financing companies to make investment choices from the seed stage.

3. If there is a difference between innovator entrepreneurs and financial managers in perceiving the importance of certain information relating to innovative projects in various stages of the project funding. 
4. If there is a greater alignment in the perception of the importance of certain information relating to innovative projects between venture capitalists and innovator entrepreneurs compared with banking system.

Therefore, this research is useful to better identify which information distortions between innovator entrepreneurs and financiers through venture capital and debt capital hinder innovative investments in Italy.

\section{Theoretical framework, previous empirical evidence, and research hypotheses}

The literature that has dealt with innovation funding in SMEs does not come to unequivocal conclusions about the importance and validity of the pecking order theory also in innovative businesses.

According to this theory, which derives from the seminal studies of Myers and Majluf (1984) and Fazzari et al. (1988), internal sources are preferred by entrepreneurs to bank debt because their use does not imply the presence of agency costs due to the informational asymmetries with the lenders (Sau 2003).

Among the external funding sources, bank debt is preferred to equity since banks professionally provide production of information relating to businesses by carrying out an activity of selection (screening) and monitoring (delegated monitoring) of investment projects. These activities diminish the degree of information asymmetry and allow the minimization of agency costs related to external funding (Diamond 1984). Moreover, bank funding, in an imperfect and inefficient market, carries out a positive signaling function for the market (Stiglitz and Weiss 1988).

To confirm this last point, several studies have shown that when a firm obtains a bank loan, there is an increase in stock prices (James 1987; Bayless and Chaplinsky 1990; Alam and Walton 1995). However, many scholars of innovative processes have pointed out that this hierarchy of funding sources should be reformulated for innovative firms and especially small ones.

With particular reference to innovative SMEs, internal funding sources may be rarely used for investment in the pre-seed and seed stages. In fact, the funding that can be collected from members is relatively low compared to the investment to be made, and also self-financing resulting from retained earnings is insufficient. Therefore, considering the residual importance of self-financing in innovative SMEs, many studies have focused on the role of external sources of innovation funding.

In particular, some empirical research on significant samples of Italian firms shows that there is an inverse relationship between the degree of leverage and intangible assets (Nucci et al. 2004). This result was interpreted as a greater degree of innovation by less indebted firms. However, other studies carried out in Italy have come to different conclusions by showing that bank funding influences positively innovation, especially in small businesses (Benfratello et al. 2008).

International empirical research does not also seem to reach a clear univocal conclusion about the relationship between leverage and innovation in firms. In fact, studies of large enterprises show that firms use more internal resources (self-financing) and less debt to fund innovative projects (Bradley et al. 1984; Titman and Wessels 1988). Other studies, more focused on SMEs, highlight the prevalence of new equity injection to fund innovative 
projects, especially in countries where the stock market is particularly developed or rapidly growing such as the USA (Carpenter and Petersen 2002) and Israel (Blass and Yosha 2003).

Finally, other surveys conducted in countries yet characterized by a remarkable development of the stock market (UK) showed that in order not to waive control rights, many entrepreneurs would be willing to fund innovation with debt capital (Aghion et al. 2004). However, these same entrepreneurs are forced to fund innovative projects by issuing new equity since they do not have sufficient internal sources (self-financing) and cannot find debt capital investors. Therefore, the conclusions reached by some studies confirm the validity of the pecking order theory (Myers and Majluf 1984) for both traditional and innovative firms, while other scholars have highlighted the need to revise the pecking order theory when an entrepreneur has to choose how to fund an innovative project (Hart 2001; Petrella 2001; Sau 2003).

In particular, some researchers point out that in the case of small innovative firms, venture capital is a source of external funding preferred by entrepreneurs to debt capital. Nevertheless, whatever the position regarding the validity of the pecking order theory with respect to innovative companies, all scholars agree on the difficulty of small firms to access 'traditional' external financing sources such as debt capital and direct collection of equity through the subscription of new shares by the old partners. Therefore, the high rate of mortality in the start-up of innovative projects is often explained by capital rationing.

Scholars have attributed these difficulties of external funding of innovative family SMEs to two major problems: (1) information asymmetries and (2) the absence of express and implied warranties.

First, the information problems related to innovation have to be taken into account. Small- and medium-sized innovative enterprises are usually newly established, and the lack of an adequate track record of quantitative economic and financial information implies a greater degree of informational opacity of these firms compared to the traditional ones. Moreover, innovator entrepreneurs cannot fully convey to the lender qualitative information about the investment project since its value decreases as the diffusion of information concerning it increases (Bhattacharya and Chiesa 1995; Anton and Yao 1998).

Effective communication of quantitative information (hard information) and qualitative information (soft information) by innovator entrepreneurs in the financial market is particularly important in funding innovative projects.

Investment decisions in the traditional financial market are particularly facilitated when there is a wide availability of objective hard information, quantifiable and readily transmissible because of being codified in written documents which are easily understood by the lender (prospective profitability of investment, time to market of the product, market interest in the product, track record related to balance sheet data). However, such information is readily available for traditional projects, but it is not available for innovative ones since historical data do not exist.

The information mostly available to innovator entrepreneurs, instead, is qualitative and difficult to codify. Such information is of a scientific and highly specialized kind and requires a high technical expertise to be understood. It is often partially codified in scientific papers which can be found in the curriculum vitae of the innovator entrepreneur and his researchers, but financial operators without a scientific background may find it 
difficult to understand them. Instead, other qualitative information related to the entrepreneur's leadership skills, the quality of business organization, or governance relationships are unlikely to be codified in written documents, and therefore, for its acquisition, a direct and long-term relationship with the innovator entrepreneur is necessary. Thus, the collection of this qualitative information requires a long time and has a higher cost than quantitative information. Hence, traditional financiers pay greater attention to qualitative rather than quantitative information. This condition is very restrictive for the funding of innovative projects.

Second, access to external funding sources is hindered by the lower availability of explicit guarantees (collateral) and implicit guarantees (cash flow expected from the project) for small innovative firms compared to traditional firms. Regarding the explicit guarantees, small innovative firms are characterized by a high incidence of intangible and firm-specific assets, which increase the risk for the potential financier (Hall 2002; Gompers 1995). The immateriality of capital does not allow the firm to provide innovative inside collateral which is able to reduce the cost of failure, while specificity in the use of intangible assets makes the decision to invest irreversibly. Regarding implied warranties, at least in the early stages, small innovative firms are not able to generate positive cash flows required for debt service (pledgeable income). This prevents lenders from possibly having guarantees in the short term about the return of debt using operating cash flow.

The abovementioned problems regarding information and guarantees related to innovation funding have led many scholars to believe that innovative firms have no access to traditional external funding sources.

In such a situation of 'market failure', small innovative firms may not find either in internal sources (self-financing) or in external sources (collection of venture capital from new partners and debt capital) the funding required to develop innovative projects.

Unlike traditional entrepreneurs, the innovator must therefore review his own order of choice of funding sources also looking for 'non-traditional' investors in certain critical stages of the project, such as the pre-seed capital, the seed capital, and start-up stages. Thus, the order of choice of funding sources for innovator entrepreneurs should be the following (Sau 2003):

1. Insider finance

2. Angel financing

3. Public financing

4. Venture capital

5. Bank financing

The order in which the sources of funding have been placed is not random as innovator entrepreneurs should gradually use the different sources of funding during the development of the project from the pre-seed stage to the expansion stage.

In particular, innovator entrepreneurs use insider finance when the innovative project is in the pre-seed stage. In this phase, the project risks related to the probability of failure and the informational opacity are so high that entrepreneurs resort to their own capital and that of their families not finding outsiders willing to finance them. The trust factor of family towards the founder entrepreneur has a key role in this phase of financing. 
The inadequacy of these internal sources, however, almost immediately compels entrepreneurs to integrate them with others coming from angel financing or public financing. Angel financing is characterized by the direct contribution of equity by an angel who is usually a wealthy retired manager willing to diversify his investments and get a good return. Considering that business angels bring personal capital and are prone to business risk, these investors fund innovative projects of limited amount and in the seed capital stage. In these cases, the literature states that external contribution of equity is possible because the knowledge of the business by the investor is very deep and he is actively involved in the operational management of the project. Despite sharing this assertion, it is believed, however, that a decisive contribution to the reduction of information asymmetries results from the fact that business angels base their funding decisions mainly on qualitative information regarding the project, being aware of the scarcity of quantitative information related to innovation.

Unfortunately, it should be noted that angel financing is still a fact of minor importance in many countries such as Italy. The scarce development of this form of financing makes it even more difficult in Italy to finance the riskiest stages of innovation development.

In those countries where angel financing is underdeveloped, public financing of innovation plays a crucial role. This source of funding is important in the seed capital stage of innovative projects, especially for the signaling function that public intervention may have towards other external funders (David et al. 2000; Klette et al. 2000). In fact, access to public funding convinces equity and debt investors of the project's validity.

Many scholars have pointed out that the main purpose of public financing is the development of competitiveness in the national economy, and this need outweighs the risk of investment. This has enabled the State to support the seed capital and start-up stages of successful innovative firms that otherwise would not have developed. Also in this case, it seems appropriate to underline that this statement is to be integrated with the finding that the State considers also soft information in its funding decisions. To confirm this statement, it is sufficient to consider that the announcements for public financing of innovative projects always require the curriculum vitae of the proposers and researchers involved in the projects.

After the seed capital stage, innovator entrepreneurs need to find more innovative sources of funding to support the start-up of the innovative project. In these phases, the risk profile and performance of the project decrease, while venture capitalists complement public financing specifically aimed at the start-up.

A venture capitalist is an intermediary that raises funds and invests them in the share capital of highly innovative firms. Having large liquid assets, the average amount of deals is much higher than for a business angel. Furthermore, by investing the funds of third parties and not their own resources, venture capitalists are more risk averse than business angels. In fact, for investment decisions, venture capitalists must consider the protection of savers and the risk profiles that are acceptable to them. For these reasons, venture capitalists intervene in the start-up stage of the innovative project, characterized by lower risk profiles than the seed stage.

Many scholars have pointed out that venture capitalists play an important activity of generation of information, generally carried out by banks in the case of funding firms that operate in traditional industries (Sau 2003). Venture capitalists perform screening and monitoring of innovative projects continuously and on a large scale, accumulating over 
time know-how in the assessment and management of projects particularly innovative industries (electronics, energy and environment, information and communications technology (ICT), life sciences, nanotechnology). So, as their intermediation activity expands, information asymmetries related to innovative products are reduced, and the ability to select projects increases compared to a generic outsider investor-funder or a bank (Ueda 2000).

These statements can be shared, but they do not consider the negative effects arising from the fact that venture capitalists are financial intermediaries that invest in equity. The need to report their investments and to ensure a minimum return to savers compels venture capitalists to attach greater importance to quantitative information (hard information) rather than qualitative information (soft information) regarding the innovative project. In fact, it is very difficult to communicate in a plausible way to the savers and the financial market the qualitative information that is the basis of investment decisions.

In that regard, in Italy many scholars have pointed out the criticality of the information relationship between innovative entrepreneurs and venture capitalists. Italian small innovative firms are characterized by a family capitalism which is inadequate to financial reporting that leads venture capitalists away from these firms.

In fact, in the screening phase of venture capitalists, family entrepreneurs fail to demonstrate to the funder the affordability of their project. This phenomenon is particularly intense in spin-off firms. The inventor entrepreneur is often a scientist who has made an academic spin-off and has deep technical knowledge of the product he is willing to launch on the market, but little economic and financial knowledge. In this respect, the academic reputation of a scientist is not a guarantee to be sufficient to compensate for the opacity of information relating to the project.

Moreover, it often happens that a venture capitalist decides not to fund a project, suspecting that the innovator entrepreneur may implement a moral hazard behavior. In fact, the founding entrepreneur may seek financial resources not to give the invention a commercial application, but to fund a further step of research in order to gain more prestige in academic circles.

The difficulties encountered by innovator entrepreneurs to access financing by venture capitalists eventually also affect access to credit, as banks interpret this event as negative signaling.

In such a situation of capital rationing, Italian innovator entrepreneurs are confined to insider finance, raising money from family members. Hence, small family spin-off firms are born; they are characterized by high innovation profiles but have a high probability of bankruptcy. In fact, once the difficult start-up phase has been bypassed, the best firms often find in public financing additional resources to overcome the pre-seed stage and enter the seed stage, but the start-up becomes a difficult phase due to the absence of additional funding sources.

In this regard, a survey conducted in Italy by Iacobucci et al. (2011) on small innovative spin-off firms highlights the growth challenges of these businesses due to lack of external sources during the start-up and development phases. According to the authors, the difficulties of raising funds are due to organizational and managerial problems, such as (1) the imbalance in the team of founders towards purely technical skills at the expense of managerial skills and (2) the lack of clarity in the definition of entrepreneurial orientation. 
In this situation, also access to credit may become difficult. The expansion phase of the innovative project is characterized by levels of risk and expected cash flow that make it more compatible with traditional sources of funding. However, banks will pay even more attention to hard information than venture capitalists. If an innovator entrepreneur does not assume a greater cultural orientation to the market and has no credible quantitative information, he is not able to access funding.

Furthermore, while venture capitalists are mainly interested to the implied warranties of the project, banks are more attentive to explicit guarantees (collateral) related to the project. This occurs because the perspective of assessment passing from venture capitalists to banks radically changes. While venture capitalists estimate the project's ability to generate greater value than other projects due to the profiles of product innovation it intends to offer, banks mainly assess the firm's ability to repay debt through total operating activities and collateral. Therefore, the innovative project is a secondary assessment factor in the bank's financing decision. So, at this stage, major information problems between funders and innovator entrepreneurs occur.

In the light of these observations, it can be stated that the difficulties of financing innovation progressively increase from the pre-seed stage to the expansion stage due to an increase in the information asymmetries between innovator entrepreneurs and the financial market. In fact, in the process of development of the innovative project from the seed capital stage to the expansion stage, the entrepreneur interacts with investors that have an increasing need of quantitative information, while he, being most often a scientist, is not able to adapt his scientific and technical language to the changing information needs of funders. This phenomenon is exacerbated when innovator entrepreneurs have to interact with the financial intermediaries (venture capitalists and banks) that have greater need for quantitative information in funding decisions compared to angel financing and public funders.

The aim of the research is to demonstrate these theoretical claims through empirical testing of the following hypotheses:

1. Business angels assign more importance to qualitative information in funding decisions related to innovative projects (H.1).

2. Public funders make funding decisions on innovative projects prevalently based on qualitative information (H.2).

3. Venture capitalists attach more importance to quantitative information when making investment decisions (H.3).

4. The banking system attaches to quantitative information a greater importance than all other external funders of innovation (H.4).

5. Innovator entrepreneurs assign greater relevance to the disclosure of qualitative information about the project when they interact with the financial market (H.5).

6. Innovator entrepreneurs ignore the increasing need of quantitative information by the financial market in the gradual transition from the seed capital stage to the expansion stage (H.6).

7. Innovator entrepreneurs find in business angels and public funders the most careful actors assessing qualitative information (H.7).

8. There is less information asymmetry between innovator entrepreneurs and venture capitalists compared with banking system (H.8). 


\section{Results and discussion}

The descriptive analysis of the data shows different perceptions of the relevance of quantitative and qualitative information regarding innovative investment projects.

In particular, an average of $35 \%$ of spin-off entrepreneurs deems quantitative information regarding innovative investment projects decisive to access external financing (Table 1). Exploring this data in depth shows that $51 \%$ of respondents believe that the information regarding prospective profitability is crucial and that only $15 \%$ attribute a key role to guarantees.

An average of $50 \%$ of business angels considers quantitative information fundamental for investment decisions. This figure is characterized by considerable variance, whereas almost all the respondents believe that information about prospective profitability (98\%) and market interest (97\%) is fundamental, while only $12 \%$ consider track record to be relevant.

Most of the public funders that were interviewed, however, do not consider quantitative information fundamental in order to make decisions about funding innovative projects. In fact, $47 \%$ believe that this type of information is decisive. Nevertheless, looking into the descriptive statistics on the answers provided by these investors, it appears that $91 \%$ of public funders consider fundamental the information on the interest of potential consumers to the innovative product to be offered. Only $25 \%$ think that time to market is important.

On the other hand, $82 \%$ of venture capitalists stated that quantitative information is crucial to investment decisions. The totality of the respondents believes that prospective profitability, time to market, and market interest are critical to investment decisions, while only $19 \%$ attach importance to guarantees.

Finally, 99\% of banks assign a decisive importance to quantitative information. This figure is characterized by a low variance because almost all of the respondents deem fundamental all the information analyzed in order to grant funding.

Turning to the analysis of the importance assigned to qualitative information, it shows that an average of $83 \%$ of the innovator entrepreneurs considers them crucial to the attraction of investors (Table 2). In particular, the totality of respondents deem fundamental the information related to their scientific curriculum and the quality of the researchers working for the firm. Only $48 \%$ of respondents consider private information decisive.

Business angels assign to qualitative information a similar importance as the entrepreneurs. In fact, $81 \%$ of these investors believe that qualitative information

Table 1 Percentage of subjects assigning crucial relevance to quantitative information

\begin{tabular}{llllll}
\hline $\begin{array}{l}\text { Quantitative } \\
\text { information }\end{array}$ & Entrepreneurs (\%) & $\begin{array}{l}\text { Business } \\
\text { angels (\%) }\end{array}$ & Public funders (\%) & $\begin{array}{l}\text { Venture } \\
\text { capitalists (\%) }\end{array}$ & Banks (\%) \\
\hline Prospective profitability & 51 & 98 & 67 & 100 & 100 \\
Time to market & 43 & 32 & 25 & 100 & 95 \\
Market interest & 43 & 97 & 91 & 100 & 100 \\
Track record & 24 & 12 & 26 & 92 & 100 \\
Guarantees & 15 & 13 & 28 & 19 & 100 \\
Average & 35 & 50 & 47 & 82 & 99 \\
\hline
\end{tabular}


Table 2 Percentage of subjects assigning crucial relevance to qualitative information

\begin{tabular}{llllll}
\hline Qualitative information & \multicolumn{5}{c}{ Interviewed subjects } \\
\cline { 2 - 6 } & Entrepreneurs (\%) & $\begin{array}{l}\text { Business } \\
\text { angels (\%) }\end{array}$ & $\begin{array}{l}\text { Public } \\
\text { funders (\%) }\end{array}$ & $\begin{array}{l}\text { Venture } \\
\text { capitalists (\%) }\end{array}$ & Banks (\%) \\
\hline Private information & 48 & 75 & 25 & 10 & 48 \\
Scientific curriculum & 100 & 94 & 94 & 98 & 25 \\
Leadership & 83 & 64 & 75 & 10 & 28 \\
Quality of researchers & 100 & 86 & 88 & 96 & 52 \\
Information system organization & 81 & 73 & 87 & 76 & 89 \\
Implementation difficulties & 95 & 78 & 78 & 78 & 87 \\
Governance relationships & 76 & 100 & 85 & 41 & 85 \\
Average & 83 & 81 & 76 & 58 & 59 \\
\hline
\end{tabular}

contributes significantly to the funding decision. In particular, business angels are attentive to governance relationships within the company $(100 \%)$ and the scientific curriculum (94\%).

On the other hand, public funders attach less importance to qualitative information compared to that observed in business angels. Of the respondents, $76 \%$ consider such information essential. Exploring the overall figure, it may be observed that $94 \%$ of respondents think that a scientific curriculum is fundamental, while $88 \%$ deem very important the quality of researchers.

Venture capitalists, however, attach much less importance to qualitative information than the other financiers so far commented. Of these investors in venture capital, 58\% consider qualitative information critical to investment decisions. In particular, $98 \%$ of the venture capitalists in the survey believe that a scientific curriculum is fundamental and $96 \%$ the quality of researchers.

Finally, credit intermediaries assign to qualitative information a similar relevance to that of venture capitalists. In fact, on average, $59 \%$ believe that qualitative information is critical to investment decisions. In particular, $89 \%$ consider fundamental the information regarding the firm's organization, while only $25 \%$ are particularly attentive to the entrepreneur inventor's scientific curriculum.

Thus, in summary, the descriptive analysis of the data shows the following:

1. Most of the spin-off entrepreneurs assign on average a greater importance to qualitative rather than quantitative information. In particular, they consider important information related to their scientific curriculum and the quality of researchers.

2. The majority of business angels attribute on average a special relevance to qualitative information. In particular, almost all business angels believe that information related to governance relationships and the scientific curriculum are decisive for investment decisions.

3. Also, most of the public funders deem fundamental the qualitative information regarding innovative projects for funding decisions. In particular, the scientific curriculum of the innovator entrepreneur and the quality of researchers have been considered particularly useful information by these financiers. 
4. Unlike other financiers so far examined, the majority of venture capitalists prefer quantitative to qualitative information. All these financiers are interested in prospective profitability, time to market, consumer studies, and track record.

5. Almost all the banks show interest in quantitative information such as prospective profitability, data related to consumer interest, track record, guarantees, and time to market.

6. There is an increasing need for quantitative information in the financial market, especially for those financiers, involved in the start-up and expansion stages of investment projects.

In order to investigate information dynamics, a comparison was made between the answers provided by innovator entrepreneurs and external funders. The judgments on the relevance of the different quantitative and qualitative information provided by the entrepreneurs may vary according to the financier to whom they are directed.

Moreover, to better highlight the differences in the evaluation of hard and soft information, it was deemed appropriate to focus the review of the results on those information variables that show a statistically significant difference in medians (significance less than 0.1 ) according to the Mann-Whitney test.

Table 3 compares the responses concerning the relevance assigned to quantitative information provided by business angels and innovator entrepreneurs. The results show significant differences in responses regarding only prospective profitability and information about market interest for the product to be marketed.

In particular, while business angels consider decisive the information regarding the prospective profitability of an innovative project, innovator entrepreneurs assign a significant but not decisive importance to such information. This difference in opinion between the two categories of respondents can be explained when considering the nature of an innovator entrepreneur. Since the latter is primarily a scientist, he considers to a lesser extent the profitability outlook of the project and mainly the experimental aspect.

The different views regarding market interest can also be explained in this light. While business angels consider decisive the interest of potential consumers for the product, this aspect is deemed less relevant by the entrepreneur.

It should be noted that other quantitative information have the same relevance for business angels and entrepreneurs. These data indicate that the information distance between these external financiers and the entrepreneurs is not so high. In particular, both entrepreneurs and business angels attach little relevance to quantitative information.

Table 3 Degree of relevance of quantitative information - comparison between business angels and innovative SMEs

\begin{tabular}{|c|c|c|c|c|}
\hline & \multicolumn{2}{|c|}{ Median relevance } & \multirow{2}{*}{$\begin{array}{l}\text { U Mann- } \\
\text { Whitney }\end{array}$} & \multirow[t]{2}{*}{ Significance } \\
\hline & Business angels & $\overline{\text { SMEs }}$ & & \\
\hline Prospective profitability & 6 & 4 & 77 & 0.0010 \\
\hline Time to market & 3 & 3 & 158 & 0.3120 \\
\hline Market interest & 6 & 3 & 64 & 0.0000 \\
\hline Track record & 3 & 3 & 170 & 0.5226 \\
\hline Guarantees & 2 & 2 & 160 & 0.3559 \\
\hline
\end{tabular}

$1=$ no relevance, $2=$ low, $3=$ medium high, $4=$ high, $5=$ very high, $6=$ decisive. 
Table 4 points out the significant differences between public funders and innovator entrepreneurs with regard to their opinion on the relevance of quantitative information for funding of innovative projects. Also, in this case, opinions differ regarding prospective profitability and market interest, while other information are evaluated in the same way by the respondents.

Public funders attach a very high importance to prospective profitability, while innovator entrepreneurs attach high relevance to this information. Moreover, public funders believe that information on market interest is very important, but entrepreneurs assign to this information a medium-high significance.

Remaining information is considered of low relevance both by entrepreneurs and public bodies.

Table 5 shows that venture capitalists and innovator entrepreneurs attribute a different relevance to all quantitative information considered in the research. In particular, venture capitalists deem decisive the assessment of prospective profitability and very relevant information about time to market and market interest. Moreover, these investors attach high relevance to track record and no importance to guarantees. These opinions differ considerably from those expressed by entrepreneurs who, with regard to quantitative information, consider only prospective profitability to be highly relevant. Therefore, conflicting views between entrepreneurs and venture capitalists may be pointed out with regard to all quantitative information taken into account.

Table 6 reveals a significant difference of opinion with regard to quantitative information that is even more relevant between banks and innovator entrepreneurs. While banks assign decisive or very high importance to all the information considered, entrepreneurs deem the same information much less important. In order to grant the credit, banks believe that information about prospective profitability and track record is crucial.

Turning to the analysis of qualitative information, Table 7 shows that only the opinions regarding private information and that related to governance relationships show a significant difference between business angels and innovator entrepreneurs. In particular, business angels attach high importance to private information, while less importance is attributed to this news by innovator entrepreneurs. Furthermore, information regarding governance relationships is considered decisive for business angels to grant credit, while innovator entrepreneurs attach less importance to this news. Nevertheless, although these differences were found, a substantial alignment of business angels and entrepreneurs in the perception of qualitative information may be pointed out. This type of data is very relevant as it highlights the importance of qualitative information in financing the innovation, especially in the pre-seed and seed stages of the project.

Table 4 Degree of relevance of quantitative information - comparison between public funders and innovative SMEs

\begin{tabular}{|c|c|c|c|c|}
\hline & \multicolumn{2}{|c|}{ Median relevance } & \multirow{2}{*}{$\begin{array}{l}\text { U Mann- } \\
\text { Whitney }\end{array}$} & \multirow[t]{2}{*}{ Significance } \\
\hline & Public bodies & SMEs & & \\
\hline Prospective profitability & 5 & 4 & 98 & 0.0040 \\
\hline Time to market & 3 & 3 & 145 & 0.1400 \\
\hline Market interest & 5 & 3 & 112 & 0.0170 \\
\hline Track record & 3 & 3 & 173 & 0.4400 \\
\hline Guarantees & 3 & 2 & 170 & 0.4740 \\
\hline
\end{tabular}

$1=$ no relevance, $2=$ low, $3=$ medium high, $4=$ high, $5=$ very high, $6=$ decisive. 
Table 5 Degree of relevance of quantitative information - comparison between venture capitalists and innovative SMEs

\begin{tabular}{|c|c|c|c|c|}
\hline & \multicolumn{2}{|c|}{ Median relevance } & \multirow{2}{*}{$\begin{array}{l}\text { U Mann- } \\
\text { Whitney }\end{array}$} & \multirow[t]{2}{*}{ Significance } \\
\hline & Venture capitalists & SMEs & & \\
\hline Prospective profitability & 6 & 4 & 54 & 0.0001 \\
\hline Time to market & 5 & 3 & 55 & 0.0001 \\
\hline Market interest & 5 & 3 & 45 & 0.0000 \\
\hline Track record & 4 & 3 & 53 & 0.0001 \\
\hline Guarantees & 1 & 2 & 39 & 0.0000 \\
\hline
\end{tabular}

$1=$ no relevance, $2=$ low, $3=$ medium high, $4=$ high, $5=$ very high, $6=$ decisive

On the other hand, in relation to public funders, Table 8 shows that there is less 'alignment' of opinions concerning the importance of qualitative information. In fact, significant differences of opinion between public bodies and entrepreneurs regard three pieces of information: the scientific curriculum, the quality of researchers, and the difficulties of implementing innovative projects.

In particular, entrepreneurs assign a decisive importance to the applicant's scientific curriculum and to the quality of researchers, while public funders believe this information is very important, but not decisive for the investment decision. Moreover, entrepreneurs attach very high importance to the difficulties of implementing the investment project, while this news is less relevant to public bodies. Nevertheless, despite these differences, there is still a substantial alignment between the opinions of public funders and entrepreneurs.

The alignment between an external financier and an innovator entrepreneur fails to materialize when the investor in question is a venture capitalist. Table 9 points out that statistically significant differences in opinions concerning the role of qualitative information in funding decisions increase significantly compared with investors previously considered. In particular, private information, the scientific curriculum, the entrepreneur's leadership, the firm's information system and organization, implementation difficulties, and governance relationships are considered in a different way by venture capitalists and entrepreneurs.

Generally, it may be noted that entrepreneurs attach a higher importance to this qualitative information than venture capitalists. The only informational alignment between venture capitalists and innovator entrepreneurs can be found in the perception of the news regarding the quality of researchers to which a decisive importance is attached.

Table 6 Degree of relevance of quantitative information - comparison between banks and innovative SMEs

\begin{tabular}{|c|c|c|c|c|}
\hline & \multicolumn{2}{|c|}{ Median relevance } & \multirow{2}{*}{$\begin{array}{l}\text { U Mann- } \\
\text { Whitney }\end{array}$} & \multirow[t]{2}{*}{ Significance } \\
\hline & Banks & SMEs & & \\
\hline Prospective profitability & 6 & 4 & 8 & 0.0000 \\
\hline Time to market & 5 & 3 & 57 & 0.0000 \\
\hline Market interest & 5 & 3 & 30 & 0.0000 \\
\hline Track record & 6 & 3 & 59 & 0.0000 \\
\hline Guarantees & 5 & 2 & 10 & 0.0000 \\
\hline
\end{tabular}

$1=$ no relevance, $2=$ low, $3=$ medium high, $4=$ high, $5=$ very high, $6=$ decisive. 
Table 7 Degree of relevance of qualitative information - comparison between business angels and innovative SMEs

\begin{tabular}{llllll}
\hline & \multicolumn{2}{c}{ Median relevance } & & $\begin{array}{l}\text { U Mann- } \\
\text { Whitney }\end{array}$ & Significance \\
\cline { 2 - 3 } & Business angels & SMEs & & 77 & \\
\hline Private information & 4 & 3 & & 77 & 0.0010 \\
Scientific curriculum & 6 & 6 & 176 & 0.8668 \\
Leadership & 4 & 6 & 166 & 0.6978 \\
Quality of researchers & 6 & 4 & 145 & 0.2898 \\
Information system organization & 4 & 5 & 159 & 0.4046 \\
Implementation difficulties & 4 & 4 & 68 & 0.2387 \\
Governance relationships & 6 & 6.0000 \\
\hline
\end{tabular}

$1=$ no relevance, 2 = low, $3=$ medium high, $4=$ high, $5=$ very high, $6=$ decisive.

Finally, Table 10 highlights that even among banks and innovative firms, there is a significant informational misalignment. The perception of qualitative information relating to all the news reviewed is different between the banking system and innovator entrepreneurs.

In general, it may be noted that banks attach less importance to qualitative information than entrepreneurs. The only information the banks deem highly relevant is that regarding the organization. In this case, however, the importance attributed by credit intermediaries to this information is higher compared to that assigned by the entrepreneur.

In summary, the comparison between the views of innovator entrepreneurs and external financiers regarding information reveals the following:

1. With regard to quantitative information, the opinions of business angels and public funders are completely aligned with those of innovator entrepreneurs. Major asymmetries are found in the perception of the relevance of quantitative information among venture capitalists, banks, and innovator entrepreneurs. In particular, it may be noted that innovator entrepreneurs ignore the increasing need of quantitative information by venture capitalists and banks for their investment decisions. Moreover, the need of quantitative information seems to be much higher for the banking system than for business angels.

2. With regard to qualitative information, there is an alignment in the opinions concerning the relevance of this information among innovator entrepreneurs, business angels, and public funders. More differences are observed, however,

Table 8 Degree of relevance of qualitative information - comparison between public funders and innovative SMEs

\begin{tabular}{|c|c|c|c|c|}
\hline & \multicolumn{2}{|c|}{ Median relevance } & \multirow{2}{*}{$\begin{array}{l}\text { U Mann- } \\
\text { Whitney }\end{array}$} & \multirow[t]{2}{*}{ Significance } \\
\hline & Public bodies & SMEs & & \\
\hline Private information & 2 & 3 & 154 & 0.3550 \\
\hline Scientific curriculum & 5 & 6 & 44 & 0.0000 \\
\hline Leadership & 3 & 4 & 147 & 0.2830 \\
\hline Quality of researchers & 5 & 6 & 133 & 0.0660 \\
\hline Information system organization & 3 & 4 & 128 & 0.1050 \\
\hline Implementation difficulties & 4 & 5 & 127 & 0.0550 \\
\hline Governance relationships & 3 & 4 & 153 & 0.2387 \\
\hline
\end{tabular}

$1=$ no relevance, 2 = low, 3 = medium high, $4=$ high, $5=$ very high, $6=$ decisive. 
Table 9 Degree of relevance of qualitative information - comparison between venture capitalists and innovative SMEs

\begin{tabular}{|c|c|c|c|c|}
\hline & Median relev & & U Mann- & Significance \\
\hline & Venture capitalists & SMES & & \\
\hline Private information & 1 & 3 & 104 & 1.0070 \\
\hline Scientific curriculum & 5 & 6 & 101 & 0.0050 \\
\hline Leadership & 2 & 4 & 43 & 0.0000 \\
\hline Quality of researchers & 6 & 6 & 155 & 0.2510 \\
\hline Information system organization & 3 & 4 & 55 & 0.0000 \\
\hline Implementation difficulties & 3 & 5 & 128 & 0.0540 \\
\hline Governance relationships & 3 & 4 & 115 & 0.0220 \\
\hline
\end{tabular}

$1=$ no relevance, 2 = low, $3=$ medium high, $4=$ high, $5=$ very high, $6=$ decisive.

comparing the views of innovator entrepreneurs with those of venture capitalists and banks. In particular, venture capitalists and banks attach less importance to qualitative information than innovator entrepreneurs.

In the light of these observations, an initial conclusion may be drawn about the information relationship between innovator entrepreneurs and external financiers: there is a greater information alignment between those investors involved in the seed stages of investment (business angels and public funders) compared to the financiers of the start-up and expansion stages of an innovative project (venture capitalists and banks). In particular, banks show a major misalignment in the perception of both quantitative and qualitative information.

\section{Conclusions}

The results of the empirical analysis confirmed the assumptions made. The interviews with external financiers and innovator entrepreneurs confirmed a different attitude towards these subjects with regard to quantitative and qualitative information.

In particular, the survey revealed special attention by external financiers involved in the pre-seed and seed capital stages of innovative projects (business angels and public funders) to qualitative information (hypotheses H.1 and H.2 confirmed). Conversely, investors involved in the later and less risky stages of the project such as the start-up and expansion of the innovative project (venture capitalists and banks) seem to be more interested in quantitative information than qualitative (hypotheses H.3 and H.4 confirmed).

Table 10 Degree of relevance of qualitative information - comparison between banks and innovative SMEs

\begin{tabular}{|c|c|c|c|c|}
\hline & \multicolumn{2}{|c|}{ Median relevance } & \multirow{2}{*}{$\begin{array}{l}\text { U Mann- } \\
\text { Whitney }\end{array}$} & \multirow[t]{2}{*}{ Significance } \\
\hline & Banks & SMEs & & \\
\hline Private information & 2 & 3 & 123 & 0.034 \\
\hline Scientific curriculum & 3 & 6 & 31 & 0.000 \\
\hline Leadership & 2 & 4 & 34 & 0.000 \\
\hline Quality of researchers & 3 & 6 & 50 & 0.000 \\
\hline Information system organization & 5 & 4 & 31 & 0.000 \\
\hline Implementation difficulties & 3 & 5 & 63 & 0.000 \\
\hline Governance relationships & 3 & 4 & 86 & 0.001 \\
\hline
\end{tabular}


In this context, innovator entrepreneurs believe that qualitative information is more relevant than quantitative information in investment decisions (hypothesis H.5 confirmed). This information approach by innovator entrepreneurs seems to have originated from the very nature of the latter. In fact, firms in the selected sample have originated from academic spin-offs. This fact implies that the selected entrepreneurs have a story and training as scientists and, probably, little business orientation. Therefore, this type of entrepreneurs wants to be valued more for their skills relating to the innovative project they proposed than for the expected future profitability and the favor of the potential consumers of the product. Furthermore, it must be noted that most of the quantitative information is of an economic and financial nature, and anyway, it is related to an assessment of the business. Scientist entrepreneurs deem this information less relevant than the quality of human resources (star scientists and researchers) involved in the project. In fact, it is well known that in the scientific world, what counts is the quality of human resources involved, rather than the economic and financial potential of the project. The more the research project is 'speculative', the more the principle is true.

These considerations bring out the different cultural orientations of the actors involved in innovation funding of spin-off firms. In fact, external financiers and innovator entrepreneurs of spin-offs seem to give a different interpretation to the expression 'success of the innovative project.' While the former interprets this expression as 'higher return on the selected investment than the alternatives available on the market', innovator entrepreneurs achieve success if 'the research and development project reaches the goal of creating a new product.' So, first of all, for a scientist, it is important to achieve the goal of creating a new product through applied research, and secondly, it is relevant to obtain a higher financial return than other projects. So, innovator entrepreneurs ignore the increasing need of quantitative information by the financial market in the gradual transition from the seed capital stage to the expansion stage (hypothesis H.6 confirmed).

Compared to this view of the relationship between external funders and innovator entrepreneurs, this research allows to make some progress. In fact, the research shows that not all external financiers have a significant cultural distance from innovator entrepreneurs. In particular, business angels and public funders appear to be close to innovator entrepreneurs, assigning greater relevance to qualitative information in investment decisions (hypothesis H.7 confirmed), while the need for quantitative information by venture capitalists and especially by banks is ignored by innovator entrepreneurs.

The distance between innovator entrepreneurs and external financiers becomes particularly relevant when the financing relationship involves credit intermediaries. In this case, informational opacity between the funder and funded becomes an obstacle to access credit, as innovator entrepreneurs seem to ignore the relevance of all the quantitative information required by the bank (hypothesis H.8 confirmed).

Finally, it is necessary to point out that the conclusions reached by this work should be read in the light of the limits of this research. In particular, it must be noted that the analyzed sample is composed of firms generated from academic spin-offs which, being founded by a star scientist, are affected by a much lower market orientation than other innovative firms. Thus, the peculiarity of the selected sample limits the possibility to extend the conclusions reached by this research, which should be tested on a sample of innovative firms of different origins. 


\section{Methods}

\section{Sample and survey variables}

The literature review on innovation funding has highlighted the importance of information problems between innovator entrepreneurs and external funders. Moreover, many researchers have observed that these difficulties tend to increase when the financing relationship involves innovative family SMEs and an external funder.

The aim of the survey is to investigate the dynamics of information asymmetries between an innovator entrepreneur who runs a family SME and external funders in the financing stages ranging from the seed capital stage to the expansion stage.

In particular, the research aims at highlighting which quantitative information (hard information) and qualitative information (soft information) are deemed relevant by entrepreneurs and external funders to evaluate an innovative project at different stages of development. Also, the aim is to check if there is a different perception of the importance of certain quantitative and qualitative information relating to innovative projects between family entrepreneurs and financial managers.

To this end, five different samples, for the year 2011, were selected, consisting of the following:

1. One hundred eighty Italian spin-off firms established through insider financing originated from the family.

2. Forty-five Italian and foreign business angels.

3. Forty-nine Italian public bodies that have provided funding for innovative companies in the last 10 years.

4. Fifty-nine Italian and foreign venture capitalists.

5. Fifty-five Italian and foreign banks.

Spin-off firms were defined as family spin-offs by reference to the presence of the founder entrepreneur's relatives in the shareholding structure. This figure was derived from the registration certificates provided by the local chambers of commerce.

Of the spin-offs that were taken into account, $85 \%$ are located in northern Italy and most of them work in the fields of information and communication technology (34\%) and life sciences (33\%) (Table 11).

Within the sample, the least represented is the nanotech industry (6\%). It is important to highlight that consistent with the nature of the selected enterprises, the sample refers to industries characterized by high innovation profiles.

Table 11 Spin-off sample of year 2011

\begin{tabular}{lll}
\hline Industries & Number & Incidence (\%) \\
\hline Electronics & 20 & 11 \\
Energy and environment & 30 & 17 \\
ICT & 61 & 34 \\
Life sciences & 59 & 33 \\
Nanotech & 10 & 6 \\
Total & 180 & 100 \\
\hline
\end{tabular}


The investigated spin-offs 'were young, since approximately 6 years on average had passed since their establishment (Table 12). Moreover, whereas the average number of employees was equal to 8.94 and the average turnover amounted to 775,000 euro, the examined spin-offs can be considered small and medium enterprises.

With regard to external funders, recalling 'non-traditional' financing sources, addressed to innovative projects, four categories of actors were selected: business angels, public funders, venture capitalists, and banks (Table 13).

Of the selected business angels, 9 were Italian and 36 were foreigners $(40 \%$ of foreigners are located in the UK, 30\% in Germany, and 30\% in France), and only the funders who invested in the areas of interest of the spin-off sample (electronics, energy and environment, ICT, life sciences, nanotech) were chosen. The information sources for the selection of business angels were the websites of the Italian Business Angels Network and the European Business Angels Network.

The 49 national and international public funders were selected by checking which development agencies had published announcements in the last 10 years for the public funding of innovative projects in the fields of interest of the spin-offs in the selected sample.

The 59 selected venture capitalists were mostly foreigners (79.7\%) and specialized in investments in the industries of the investigated spin-offs, while the Italians were Savings Management Companies (Società di Gestione del Risparmio) created by banks. The main information sources for the identification of the firms were the AIFI website and the European Private Equity and Venture Capital Association websites.

Finally, the 55 banks that were examined are mainly Italian (58.2\%) and are large banks that operate nationwide.

For the various selected samples, a questionnaire composed of two parts was administered. The first part was a registry that included essential information concerning the respondent, while the second included closed-ended questions.

In the second part of the questionnaire, it asked to express an opinion on the relevance of certain categories of quantitative information (hard information) and qualitative information (soft information) to assess the funding worthiness of the innovative projects (Table 14).

The questionnaire was structured using the Likert scale with 6 increasing scores: $1=$ no relevance of the information, $2=$ low relevance, $3=$ average relevance, $4=$ high relevance, $5=$ very high relevance, and $6=$ decisive relevance .

The questionnaire administered to innovator entrepreneurs asked them to give a different judgment for each type of funder (angel investors, public funders, venture

Table 12 Features of spin-off enterprises

\begin{tabular}{llll}
\hline Industries & $\begin{array}{l}\text { Average number of years } \\
\text { since establishment }\end{array}$ & $\begin{array}{l}\text { Average number of } \\
\text { employees }\end{array}$ & $\begin{array}{l}\text { Average turnover } \\
\text { (thousands of euro) }\end{array}$ \\
\hline Electronics & 7.2 & 9.2 & $1,329.40$ \\
Energy and environment & 6.3 & 6.5 & 372.80 \\
ICT & 8.1 & 9.3 & $1,069.60$ \\
Life sciences & 7.3 & 10.2 & 701.20 \\
Nanotech & 5.5 & 9.5 & 402.70 \\
Average & 6.9 & 8.9 & 775.14 \\
\hline
\end{tabular}


Table 13 Sample of external funders of innovative projects

\begin{tabular}{lllll}
\hline & Italian & Foreigner & Total & Incidence (\%) \\
\hline Business angels & 9 & 36 & 45 & 21.63 \\
Public funders & 19 & 30 & 49 & 23.56 \\
Venture capitalists & 12 & 47 & 59 & 28.37 \\
Banks & 32 & 23 & 55 & 26.44 \\
Total & 72 & 136 & 208 & 100.00 \\
\hline
\end{tabular}

capitalists, banks). Therefore, the degree of importance assigned by an entrepreneur to the same type of information may vary depending on the funder to which it relates.

The survey variables obtained from the responses to the questionnaires that were administered can be divided in two categories: (1) hard variables and (2) soft variables.

The variables defined as 'hard information' are specified as follows:

- Prospective profitability indicates the relevance of information regarding the expected future profitability and the value created by the investment project estimated through the use of known techniques of capital budgeting. Several studies have highlighted the importance of these techniques for non-traditional venture capital funders such as venture capitalists. Other scholars have pointed out the difficulties encountered by innovator entrepreneurs in producing these types of information.

- Time to market measures the relevance of quantitative data relating to the time necessary to transform an invention into a marketable product. This type of data is quantifiable and objective although it is subject to a considerable variance. This type of quantitative data summarizes an important element of risk attached to innovation. In some innovative industries such as life sciences, the time between testing and marketing is so long and uncertain that it affects the financial viability of the project.

Table 14 Survey questions

\begin{tabular}{|c|c|}
\hline Question & Specific item \\
\hline \multirow[t]{5}{*}{$\begin{array}{l}\text { A. Indicate the degree of importance assigned } \\
\text { to the following quantitative information regarding } \\
\text { innovative projects for the investment decision }\end{array}$} & $\begin{array}{l}\text { 1. Expected investment profitability and estimated } \\
\text { creation of value through the techniques of capital } \\
\text { budgeting (VAN, TIR...) }\end{array}$ \\
\hline & $\begin{array}{l}\text { 2. Estimated time to convert the patent and/or the } \\
\text { prototype in a marketable product/service }\end{array}$ \\
\hline & $\begin{array}{l}\text { 3. Quantitative analysis of the market to estimate the } \\
\text { interest of potential customers for the new product }\end{array}$ \\
\hline & $\begin{array}{l}\text { 4. Historical data related to the economic and financial } \\
\text { performance of the firm in previous years }\end{array}$ \\
\hline & 5. Personal guarantees and collateral of the proposer \\
\hline \multirow{6}{*}{$\begin{array}{l}\text { B. Indicate the degree of importance assigned to } \\
\text { the following qualitative information regarding } \\
\text { innovative projects for the investment decision }\end{array}$} & 1. Private information about the entrepreneur \\
\hline & 2. Scientific curriculum of the entrepreneur \\
\hline & 3. Leadership skills of the entrepreneur towards his employees \\
\hline & $\begin{array}{l}\text { 4. Organization of the firm and quality of the information } \\
\text { system }\end{array}$ \\
\hline & $\begin{array}{l}\text { 5. Degree of difficulty in the technical implementation } \\
\text { related to the industrial manufacturing of the prototype }\end{array}$ \\
\hline & 6. Personal relationships among family partners \\
\hline
\end{tabular}


- Market interest detects the influence of the information contained in marketing studies on consumer guidelines. Large innovative companies heavily invest in market research to monitor the needs of consumers and diminish the risk of failure of a new product. Small- and medium-sized enterprises often lack the financial resources to carry out studies in this direction and rely on market data produced by research institutes.

- Track record indicates the importance of the trend of historical economic and financial data regarding the firm on funding decisions. This is a very important critical element in the relationship between small businesses and external funders. In fact, the most risk-averse external investors have difficulty assessing the financial viability of an innovative project because of a lack of historical data both regarding the proposing firm, which is often newly established, and the trend of the product it intends to sell, as the latter is not on the market yet.

- Guarantees measure the importance of economic and financial information on those who have provided personal guarantees and collateral in the interest of the innovative firm.

The variables defined as 'soft information' are specified as follows:

- Private information measures the importance assigned to private information on the firm's performance released by the entrepreneur himself or by those close to him such as the stakeholders. This information includes the age of the entrepreneur, his history, his relations with the world of research and industry, and the views expressed by those who have spent time with him in the workplace or privately. This information may be a proxy for relational and social capital that the innovator entrepreneur has been able to accumulate in his own environment.

- Scientific curriculum measures the influence exerted by qualitative information on the scientific activity of an entrepreneur founder of the spin-off. In this case, it is not only monographs, papers in journals, contributions to collective works, and reports at conferences that the entrepreneur produced during his academic career, but also the information that cannot be encoded in written documents and is available only by spending time directly with the scientist. An intense scientific profile consistent with the activities undertaken as an entrepreneur is an index of the spin-off's ability to innovate.

- Leadership measures the importance of employees' trust in the innovator entrepreneur's ability. Beyond the role of employer that gives a right to command, there are other non-institutional factors that may influence employees to follow an entrepreneur in new risky activities. In particular, employees' trust derives from the modes of action, transparency, and success stories experienced by these people together with the innovator entrepreneur.

- Quality of researchers measures the importance attached to information about the know-how of the researchers employed in the spin-off. This information relates to the scientific curriculum and the ability to produce applied research. Several studies have highlighted the relevance of this information in innovative 
businesses as an element to assess human capital and the competitive potential of the spin-off.

- Information system organization measures the influence of information on the quality of the business organization and the information system. The organizational aspect is of great importance in the innovation process. Very frequently in spin-offs, an organization is informal and tends to replicate that of the research teams. However, if an informal organization can be useful in the context of research, the same may not occur inside an innovative company. In fact, the lack of a functional specialization in performing tasks could adversely affect the cost of producing the good.

- Implementation difficulties indicate the importance attached to the news about the possible technical difficulties in the transition from prototype to industrial production. In fact, it sometimes happens that at this stage, technical production difficulties arise or production costs prove to be higher than those estimated.

- Governance relationships measure the importance attached to information concerning the relationship between a founder entrepreneur and his family members who have participated in the creation of the enterprise by providing personal capital.

\section{Methodology for data processing}

The results of the survey sampling were analyzed by descriptive analysis and the Mann-Whitney statistical test.

Descriptive analysis was used to check whether innovator entrepreneurs, business angels, and public funders attach more importance to qualitative rather than quantitative information, while the opposite occurs for venture capitalists and the banking system (hypotheses H.1, H.2, H.3, H.4, and H.5).

Considering the small sample size, the non-parametric Mann-Whitney test was used in order to point out the existence of statistically significant differences among the responses provided by innovator entrepreneurs of spin-offs and those provided by external funders with respect to the variables previously described.

In particular, non-parametric test results must show the following: (1) whether innovator entrepreneurs ignore the increasing quantitative information need of the financial market in the gradual transition from the seed capital stage to the expansion stage (H.6), (2) if innovator entrepreneurs find in business angels and public funders those most attentive to the assessment of qualitative information (H.7), and (3) if there is less information asymmetry between innovator entrepreneurs and venture capitalists compared with banking system (H.8).

The Mann-Whitney $U$ test (Mann-Whitney, 1947) or robust rank-order test is a non-parametric statistical test (it does not require a priori assumptions about the characteristics of the population) and is equivalent to $t$ statistics for independent samples. It is used to test the null hypothesis that two samples come from the same population (have the same median) or, alternatively, if the observations belong to two different populations (they have different medians).

The Mann-Whitney test arises from H. B. Mann and D. R. Whitney's proposal to generalize Wilcoxon's method (Wilcoxon, 1945) and requires no assumptions about 
the symmetry of the two samples. Moreover, it can also be applied when the two samples have different sizes. The Mann-Whitney test is divided into the following steps:

Step 1. Sorting data in ranks ${ }^{a}$ (r), including the two samples in the same order. If samples are not balanced, we say that the size of the smallest sample is $n$ and the size of the largest is $m$. The sum of the ranks of the two samples is

$$
\Sigma_{r}=\frac{(n+m)(n+m+1)}{2} .
$$

The null hypothesis of random assortment of values in the two groups provides that both groups have the same mean rank $r_{m}$, that is,

$$
r_{m}=\frac{(n+m)(n+m+1)}{2} \frac{1}{n+m}=\frac{n+m+1}{2} .
$$

Multiplying the mean rank by the respective sample sizes, the sum of the ranks expected for the condition of indifference is obtained.

Step 2. Summing the ranks of the smaller sample $(U)$. This amount is already the result of the test. In fact, the more the sum of the ranks of the smaller sample differs from the expected one, the more the probability that the two samples are random assortments of ranks loses consistency. The verification in the table will tell us whether to keep or reject the null hypothesis beyond the different critical thresholds of significance. For each level of significance, two extreme values are inscribed in the table: a very small and a very large one. The significance is reached if $U$ is smaller than the smallest value or higher than the highest value in the table. If the samples are large enough, it is possible to do without the table and exploit the fact that $U$ tends to be normally distributed around the expected value of the null hypothesis:

$$
z_{U}=\frac{U-m_{U}}{s_{U}},
$$

where

$$
\begin{aligned}
& m_{U}=n \frac{n+m+1}{2}=n r_{m} \\
& s_{U}=\sqrt{\frac{n \cdot m(n+m+1)}{12}}
\end{aligned}
$$

Formulas 4 and 5 are respectively the mean rank multiplied by the sample size of the first group and the standard deviation. If $Z_{U}$ exceeds an absolute value of 1.96, the two groups may be considered significantly different.

\section{Endnote}

${ }^{a}$ The rank represents the increasing ordered position of observations. 


\section{Authors' contributions}

FC authored the background and the summary literature review. MDG structured the research methodology. MRDP wrote the results, discussion and conclusions. All authors read and approved the final manuscript.

\section{Received: 24 February 2013 Accepted: 12 July 2013}

Published: 17 July 2013

\section{References}

Aghion, P, Bond, S, Klemm, A, \& Marinescu, I. (2004). Technology and financial structure: are innovative firms different? Journal of the European Economic Association, 4, 277-288.

Alam, P, \& Walton, KS. (1995). Information asymmetry and valuation effects of debt financing. Financial Review, 30, 289-311.

Anton, J, \& Yao, D. (1988). The sale of intellectual property: strategic disclosure, property rights and incomplete contracts. The Wharton School of the University of Pennsylvania: Working Paper.

Bayless, M, \& Chaplinsky, S. (1990). Expectations of security type and the information content of debt and equity offers. Journal of Financial Intermediation, 1, 195-214.

Benfratello, L, Schiantarelli, F, \& Sembenelli, A. (2008). Banks and innovation: microeconometric evidence on Italian firms. Journal of Financial Economics, 90, 197-217.

Bhattacharya, S, \& Chiesa, G. (1995). Proprietary information, financial intermediation and research incentives. Journal of Financial Intermediation, 4, 328-357.

Blass, AA, \& Yosha, O. (2003). Financing R\&D in mature companies: an empirical analysis. Economics of Innovation and New Technology, 12(5), 425-447.

Bradley, M, Jarrel, GA, \& Kim, EH. (1984). On the existence of an optimal capital structure: theory and evidence. Journal of Finance, 39(3), 857-881.

Carpenter, R, \& Petersen, B. (2002). Capital market imperfections, high-tech investments and new equity financing. The Economic Journal, 112(1), 54-72.

David, PA, Hall, BH, \& Toole, A. (2000). Is public R\&D a complement or a substitute for private R\&D? A review of the econometric evidence. Research Policy, 29, 497-530.

Diamond, D. (1984). Financial intermediation and delegated monitoring. Review of Economic Studies, 51, 393-414.

Fazzari, S, Hubbard, G, \& Petersen, BC. (1988). Financing constraints and corporate investment. Brookings Papers on Economic Activity, 1, 141-205.

Gompers, P. (1995). Optimal investment, monitoring and the staging of venture capital. Journal of Finance, 50, 1461-1489.

Hall, B. (2002). The financing of research and development. Oxford Review of Economic Policy, 18(1), 35-51.

Hart, O. (2001). Financial contracting (p. 8285). Working Paper: NBER.

lacobucci, D, lacopini, A, Micozzi, A, \& Orsini, S. (2011). Fostering entrepreneurship in academic spin-offs. International Journal of Entrepreneurship and Small Business, 12, 513-33.

James, C. (1987). Some evidence on the uniqueness of bank loans. Journal of Financial Economics, 19, 217-235.

Klette, TJ, Moen, J, \& Griliches, Z. (2000). Do subsidies to commercial R\&D reduce market failures? Microeconomic Evaluation Studies. Research Policy, 29, 471-496.

Myers, SC, \& Majluf, NS. (1984). Corporate financing and investment decisions when firms have information that investors do not have. Journal of Financial Economics, 13, 187-221.

Nucci, F, Pozzolo, A, \& Schivardi, F. (2004). Is firm productivity related to its financial structure? Evidence from microeconomic data. Rivista di politica economica, 95(1-2), 177-98.

Petrella, G. (2001). Sistemi Finanziari e Finanziamento delle Imprese Innovative (p. 4). Quaderni REF: Profili Teorici ed Evidenze Empiriche Dall'Europa.

Sau, L. (2003). Working Paper prepared for the Conference: Innovate to compete. Novara: ow to fund innovation?: Gli effetti del Venture capital sulle gerarchie di finanziamento delle imprese innovative (pp. 22--23).

Stiglitz, J, \& Weiss, A. (1988). Banks as social accountants and screening devices for the allocation of credit (p. 2710). NBER Working Paper.

Titman, S, \& Wessels, R. (1988). The determinants of capital structure choice. Journal of Finance, 43(1), 1-19.

Ueda, M. (2000). Bank versus venture capital. Working Paper: Universitat Pompeu Fabra (UPF).

doi:10.1186/2192-5372-2-18

Cite this article as: Campanella et al:: Informational approach of family spin-offs in the funding process of innovative projects: an empirical verification. Journal of Innovation and Entrepreneurship 2013 2:18. 